\title{
EXPERIENCE IN THE REVIEW OF UTILITY CONTROL ROOM DESIGN REVIEW AND SAFETY \\ PARAMETER DISPLAY SYSTEM PROGRAMS
}

BY

Voss A. Moore

\subsection{Background}

The Detailed Control Room Design Review (DCRDR) and the Safety Parameter Display System (SPDS) had their origins in the studies and investigations conducted as the result of the TMI-2 accident. The President's Commission (Kemeny Commission) I/ critized NRC for not examining the man-machine interface, over-emphasizing equipment, ignoring human beings, and tolerating outdated technology in control rooms. The Commission's Special Inquiry Group (Rogovin Report) 2/ recommended greater application of human factors engineering including better instrumentation displays and improved control room design. The NRC Lessons Learned Task Force $3 /$ concluded that licensees should review and improve control rooms usine NRC Human engineering guidelines, and install safety parameter display systems (then called the safety staff vector). The TMI Action Plan 4/ Item I.D.I and I.D.2 were based on these recommendations.

The TMI Action Plan called for NRC to require that operating reactor licensee and applicants for operating licensees perform a detailed control room design review to identify and correct design deficiencies. The review should include an assessment of control room layout, the adequacy of the information provided, the arrangement and identification of important controls and instrumentation displays, the usefulness of the audio and visual alarm system, the information recording and recall capability, lighting, and other considerations of human factors that have an impact on operator effectiveness. The detailed control room design review was expected to take more than a year. Therefore, NRC should require that those applicants for operating licenses who are unable to complete the detailed review prior to fuel loading make a preliminary assessment of their control room to identify significant human factors and instrumentation problems and establish a schedule approved by NRC for correcting deficiencies. These applicants are also required to complete the more detailed control room review after licensing. Prior to the initiation of the detailed reviews, NRC was to formulate design review guidelines to be used by licensees and applicants to assist in the identification of design weaknesses.

The Action Plan also called for NRC to require, in conjunction with the control room design upgrade, all licensees and applicants to install a safety parameter display system to display to operating personnel a minimum set of parameters which define the safety status of the plant. The system should have the capability of displaying a full range of important plant parameters and data trends on demand.

In September 1981 the NRC issued "Guidelines for Control Room Design Reviews," NUREG-0700 5/ for use by utilities in conducting detailed control room design reviews. NUREl-0700 comsists of accepted human factors guidelines, developed principally by military and space programs, adapted to nuclear control rooms. Additional guidelines were developed where non existed that met the control room needs. The guidelines were initially issued in draft form for public comment $\underline{6,7 /}$ and were the subject of two days of public meetings.
During the formative stages of the detailed control room design review (DCRDR) and safety parameter display system (SPDS) program, industry initiated a number of activities. The IEEE initiated a Working Conference on Electrotechnology Applications to Nuclear Power Plants which was held in Washington, D.C. January 15-17, 1980 8,9/ under the joint sponsorship of IEEE and NRC. This conference brought together engineers from a number of industries to focus on nuclear power plant applications. Two IEEE standards Workshops on Human Factors and Nuclear Safety 10,11/ (Myrtle Beach Conferences) were held December 2-7, 1979, and August 30-September 4, 1981. INPO and EPRI held several workshops.

\subsection{NRC Requirements and Review}

The formal NRC requirements for the DCRDR and SPDS are contained in NUREG-0737, Supplement 1 12/ which was transmitted to the industry by Generic Letter 82-33 on December 17, 1982. NUREG-0737, Supplement 1, contains technical and documentation requirements and outlines an approach for negotiated schedules that will become enforceable. NUREG-0737, Supplement I, reiterates that previously issued guidance documents such as NUREG-0700 have been issued for guidance to the industry and NRC staff and are not NRC requirements. The Commission approved requirements are contained in NUREG-0737, Supplement 1. However, as stated in Generic Letter 82-33, NUREG-0737, Supplement 1 , is a distillation of basic requirements from the guidance documents.

Generic Letter 82-33 required licensees and applicants to propose schedules for completing each of the basic requirements of NUREG-0737, Supplement 1, no later than April 15, 1983. These schedules were proposed; have been discussed with the NRC project managers and in some cases modified; and orders have been issued to most licensees making the schedules enforceable. For applicants for operating licenses, the schedules are made enforceable through license conditions.

\section{I DCRDR Requirements}

NUREG-0737, Supplement 1 , requires that licensees and applicants conduct a detailed control room design review that consists of:

1. Establishment of a qualified multidisciplinary review team

2. Function and task analyses to identify control room operator tasks and information and control requirements during emergency operations.

3. A comparison of display and control requirements with a control room inventory

4. A control room survey to identify deviations from accepted human factors principles

5. Assessment of human engineering discrepancies (HEDs) to determine which HEDs are significant and should be corrected

6. Selection of design improvements 
7. Verification that selected design improvements will provide the necessary correction

8. Verification that improvements will not introduce new HEDs

9. Coordination of control room improvements with changes from other programs such as SPDS, operator training, Reg. Guide 1.97 instrumentation, and upgraded emergency operating procedures.

NUREG-0700 provides guidance concerning most of these requirements. For example, Sections 2.2 and 2.3 of NUREG-0700 provide guidance for establishing a multidisciplinary team, 3.4 and 3.7 for function and task analysis, 3.5 for control room inventory, and Sections 3.6 and 6 for the control room survey. It should be repeated, however, that the guidance of NUREG-0700 does not constitute requirements and alternative approaches may be found acceptable.

In addition to technical requirements, NUREG-0737, Supplement 1, contains documentation requirements. Submittal of a Program Plan to NRC is required early in the DCRDR process. The Program Plan describes how the licensee or applicant plans to meet the requirements of the DCRDR. In effect it describes his methodology.

Licensees and applicants are required to submit a summary report of the completed review outlining proposed control room changes, including their proposed schedule for implementation. The report also provides a summary justification for human engineering discrepancies with safety significance to be left uncorrected or partially corrected.

\subsection{NRC Review of DCRDRs}

NUREG-0737, Supplement 1, outlines the NRC review process. The review includes the following elements:

\section{Review and provide comments on Program Plans \\ 2. Conduct on-site in-progress audits of selected DCRDRs}

3. Review Summary Reports and develop Safety Evaluation Reports

4. Conduct on-site pre-implementation audits of selected DCRDRs.

Program Plans require no NRC approval. However, based on its review, NRC provides written comments to licensees and applicants identifying areas which in NRC judgment require strengthening in order to meet NRC requirements. The comments also identify elements which if carried out as described should accomplish the objectives of the DCRDR. The Program Plan also aids NRC in selecting DCRDRs for on-site in-progress audits and in establishing the agenda for the audit.

During on-site in-progress audits the NRC staff meets with the licensee/applicant review team, observes reviews in progress, reviews licensee/applicant DCRDR records and tours the control room. At the conclusion of the audit NRC issues an audit report for use by the licensee/applicant in completing its DCRDR.

The NRC staff approves, approves with comments, or disapproves the licensee/applicant's DCRDR, proposed changes, and proposed schedule in its Safety Evaluation Report (SER). The Summary Report, Program Plan, and any on-site audits and other meetings form the basis for the SER.

On-site pre-implementation audits are similar to inprogress audits except they are conducted after the DCRDR has been completed but prior to implementation of major control room modifications.

\subsection{SPDS Requirements}

The requirements of NUREG-0737, Supplement 1, are general. Each operating reactor is required to be provided with a Safety Parameter Display System located so that it is convenient to the control room operators. The system will continuously display information from which the plant safety status can be assessed by control room personnel who are responsible for avoidance of degraded and damaged core events. The SPDS should provide a concise display of critical plant variables to the control room operators to aid them in rapidly and reliably determining the safety status of the plant. Minimum information to be provided shall be sufficient to provide information to plant operators about:
1. Reactivity control
2. Reactor core cooling and heat removal from the primary system
3. Reactor coolant system integrity
4. Radioactivity control
5. Containment conditions.

The SPDS display shall be disigned to incorporate accepted human factors principles so that the displayed information can be readily perceived and comprehended by SPDS users. The SPDS shall be suitably isolated from electrical and electronic interference with equipment and sensors that are used for the safety system.

\subsection{NRC Review of SPDSs}

Prompt implementation of well designed safety parameter display systems in operating reactors is a goal of primary importance. The review process for operating reactors called for in NUREG-0737, Supplement 1 , is designed to avoid delays resulting from the time required for NRC staff review. The NRC staff will not review operating reactor SPDS designs pursuant to Supplement 1 of NUREG-0737 before implementation unless a licensee has specifically requested a pre-implementation review. The licensee's safety analysis and SPDS implementation plan will be reviewed by the NRC staff only to determine if a serious safety question is posed by the proposed system or if the analysis is seriously inadequate. The NRC staff review to accomplish this will be directed at ( 1 ) confirming the adequacy of the variables selected for display to assess critical safety functions, (2) confirming that means are provided to ensure that the data displayed are valid, (3) confirming that the licensee has committed to a humanfactors engineering program to ensure that the displayed information can be readily perceived and comprehended so as not to mislead the operator, and (4) confirming suitable isolation from electrical or electronic interference with equipment and sensors that are used for safety systems. If, on the basis of this review, the staff identifies a serious safety question or seriously inadequate analysis, the Director of IE or the Director of NRR may request or direct the licensee to correct the deficiency or even to cease implementation. 
The NRC staff review for serious safety questions or inadequate analysis may identify human engineering discrepancies that do not constitute serious safety questions. However, correction of these discrepancies could enhance effectiveness and improve operating crew acceptance. The NRC staff Safety Evaluation Report will recommend evaluation of the identified discrepancy by the utility.

For reviews of operating licensee applications (OL reviews) and for operating reactors for which the licensee has requested a pre-implementation review of the SPDS design, the NRC staff will review for compliance with the basic elements set out in Supplement 1 of NUREG-0737. For such reviews, the NRC staff will initially evaluate the applicant/licensee's verification and validation (V\&V) program plan and will audit the results of its design verification activities. Subsequently, the staff will audit the applicant/ licensee's design validation program, test plans, and test results. During each audit, the staff plans to review safety analysis data and human-factors engineering design data prepared by the applicant/licensee as well as to review its V\&V activities. For pre-implementation reviews, the NRC staff intends to conduct the review in two audit meetings with the applicant/ licensee during the period of SPDS design and design validation tests. The staff will document its findings after each meeting.

\subsection{NRC Experience with DCRDR and SPDS Programs}

\subsection{DCRDR Programs}

In discussing NRC's experience in the review of DCRDRs performed by utilities, I would like to consider each of the nine NUREG-0737, Supplement 1 requirements. A discussion of issues usually tends to concentrate on problems, disagreements, and misunderstandings. This seems particularly true when an NRC representative is conducting the discussion. A discussion of problems and the negative aspects of a program is necessary for a useful exchange of information. However, I would like also to make positive observations in order to present a balanced picture.

Almost none of the observations I will be making apply to all units and programs of all utilities. This is not surprising because ultimately NRC's reviews will consider approximately 128 units and the programs of approximately 57 utilities. My observations therefore, will be general impressions of the program to date.

The NRC staff now knows more about the plans and proposed programs of utilities than it does of completed programs and control room improvements. This is because we have reviewed far more Program Plans than Summary Reports of completed reviews. We have reviewed Programs Plans covering approximately 108 control rooms of approximately 50 utilities. The Program Plans reviewed to date cover about 85 percent of the control rooms of operating units and units undergoing operating license review. In contrast, we have reviewed Summary Reports covering only about 15 control rooms and for many of these reviews there are still open issues.

One impression I have is that many utilities have a serious desire to improve their control rooms. I sense that many programs place their highest priority on reducing the potential for operator error and a lesser priority on meeting minimum NRC requirements. This attitude, I believe, will result in improved control rooms, fewer operator errors, better availability, and fewer safety problems. This attitude is evidenced in a number of ways. Most programs involve thorough operator questionaires and interviews and careful consideration of comments of operators. Operators who traditionally take pride in being able to operate effectively in the control room that was provided them also seem to be enthusiastic about improvements and are making careful recommendations. A number of programs deliberately go beyond NRC requirements, for example, normal and abnormal operations as well as emergency operations are considered in some function and task analysis programs. Most reviews are considing shutdown capability outside the control room.

Utilities generally appear to be meeting the requirement to establish a qualified multidisciplinary team. However, Program Plans frequently are unclear as to which tasks involve the various disciplines. Usually, however. further discussion has revealed that the assignments are appropriate. In a very few cases, we have found not enough utility involvement, particularly utility management, with the review team.

Function and task analysis has resulted in more NRC comments and meetings than any other of the NUREG-0737, Supplement 1, requirements. There are probably several reasons for the difficulty. The first is that different levels of task analysis went into the development of generic technical guidelines for emergency operating procedures by the different owners' groups. Since NUREG-0737, Supplement 1, permits utilizing the function and task analysis that went into the development of generic technical guidelines, the amount of plantspecific task analysis depends on which generic technical guidelines apply. To aid in clarifying this issue, meetings were held with the Westinghouse Owners' Group 13/, the General Electric Owners' Group 14/, and the Combustion Engineering Owners' Group 15/. The level of task analysis performed by each Owners' Group was discussed and was summarized in the meeting minutes. A meeting is scheduled for November 15, 1984, with the Babcock and Wilcox Owners' Group.

The purpose of the DCRDR function and task analysis is to identify the control and display requirements during emergency operation. Many programs appeared initially to have been geared to identifying the displays and controls provided for emergency operation rather than those that are needed. This misinterpretation has resulted in a number of proposed function and task analyses being limited to a walk through of emergency operating procedures. Walk throughs are useful in assuring the compatibility of the procedures and the display controls after both have been upgraded. However, before the walk through phase can be effective an analysis that defines the display and control needs for each operator task in emergency operations is needed. The programs we believe to be most effective include a desk top exercise involving an operator, a systems engineer, and a human factors professional in which each operator task is listed in detail. For each operator task, the display and control needs are identified and their characteristics defined. This completed list is then compared to the controls and displays available in the control room. The requirement for a comparison of display and control requirements with a control room inventory is generally adequately met by the utilities proposing satisfactory function and task analysis programs.

Our review of programs to meet the requirements for a control room survey to identify deviations from accepted human factors principles has detected few generic problems. The guidelines of NUREG-0700, Section 6, are reasonably clear and fairly detailed. Other acceptable guidelines for the survey are available in the human factors literature. Most utilities 
appear to be using NUREG-0700 in their surveys although some take specific exception to certain guidelines.

Most utilities seem to have developed adequate programs for the assessment of human engineering discrepancies (HEDs) to determine which HEDs are significant and should be corrected. The same is true for the prom grams for the selection of design improvements, The difficulty in this area often has been in clearly describing the programs in summary form in Program Plans. However, our on-site audits have led us to conclude that most programs audited were satisfactory, As might be expected, a finding by NRC of adequacy of these programs, does not necessarily mean that NRC will always agree with the results of the review in detail.

Many utilites used mockups for verifying that selected design improvements provide the necessary correction and do not introduce new HEDs.

The program for coordination of control room improvements with changes from other programs such as SPDS, operator training, Regulatory Guide 1.97 instrumentation, and upgraded emergency operating procedures proposed by a number of utilites needed improvement. The team developing improved emergency operating procedures and the DCRDR team often seemed to have inadequate communications. In several instances the schedules for the different programs did not permit optimum interaction. Several programs, however, appeared to provide good coordination by using a management group composed of the leaders of each of the efforts to review and approve the work involving all of the NUREG-0737, Supplement 1, effort.

\subsection{SPDS Programs}

As previously stated, NRC is performing two types of SPDS reviews. For plants undergoing review for issuance of an operating license, the staff performs a pre-implementation review for conformance with the requirements of NUREG-0737, Supplement 1. On request of operating reactor licensees and vendors with generic SPDS designs, the NRC performs a pre-implementation review similar to that performed for operating license reviews. The review of operating reactor SPDSs where no pre-implementation review has been requested is a much more abbreviated review. This review is only to determine if a serious safety question is posed by the licensee's proposed system or if the licensee's analysis is seriously inadequate.

Of the more detailed SPDS reviews, the staff has completed two SPDS reviews for plants under operating license review. A number of other such reviews are in progress. The design verification review of the Westinghouse generic SPDS has been completed. The review of the General Electric SPDS (Emergency Response Information System - ERIS) is in progress. The licensees for four operating plants have requested pre-implementation reviews, two of which are presently in progress.

The safety analysis and implementation plans of SPDSs for 43 operating units not requesting pre-implementation reviews have been reviewed. These reviews have resulted in the issuance of Safety Evaluation Reports for 11 units and requests for additional information concerning 32 units. In each of the Safety Evaluation Reports issued to date, the staff concluded that continued implementation of the SPDSs may proceed. However, in a number of the evaluations, the staff made recommendations to be considered during SPDS implementation.
Several years ago the NRC staff believed that there would be a relatively small number of standard SPDS designs. The basis for this belief was the cost of software and hardware verification and validation programs. Later, however, meetings with EPRI and others revealed that in excess of twenty vendors had announced their intention of marketing SPDSs. A recent check of the SPDS submittals for 62 nuclear units revealed that ten vendors are supplying the SPDSs for 38 of the units, and the SPDSs for 24 of the units are in-house designs. In almost all cases where vendor designs are being used, there are fairly significant plant-specifc variations. It now appears that there will be more vendor designs that we initially expected, but fewer than the 20 that later appeared possible. However, because of the plant specific variations of vendor designs and the number of in-house designs, there will be a large number of designs and design variations to be reviewed by the NRC staff.

Our reviews of SPDS programs have revealed some encouraging signs. Many utilities seem to be pursuing their SPDS Programs with enthusiasm with the expectation that the SPDS will improve control room operation. In a number of cases the SPDS is only a part of a general upgrade in the ability to manage data and information for control room operators through the use of computers.

There appears to be some excellent work being done in the development of systems for validating data to be displayed on SPDSs. The extent to which this $R$ and $D$ validation will be applied in the industry as a whole is unknown. The validity of the data displayed on the SPDS is extremely important. The advantage of a concise display of the safety status of the plant could be lost if the operating staff were misled by invalid data being displayed on the SPDS. Data validation is especially important because the SPDS is not required to meet the single failure criterion and certain other safety criteria. Individual designers have developed software for data validation. In addition, an EPRI/ Utility group is performing a study of data validation techniques.

We have seen several excellent display formats indicating that human factors were considered in the design process. Further evidence of good human factors design are the function-based keyboard designs that facilitate accessing SPDS information. We are also aware of a number of good verification and validation programs that follow closely the program outlined in NSAC-39 16/. A number of programs have included operator input and involvement in the SPDS development. In addition to improving the quality of the SPDS, operator involvement should improve the acceptance of the SPDS by the operating crews.

The bad features we have seen do not appear to be generic. We have seen a few cluttered top level displays. There are instances of labeling, nomenclature, and color conventions on SPDSs that are at odds with those on the control boards. In a few cases we find that verification and validation is not implemented in the early phase of software development with the expectation of finding errors in later integrated testing. We believe that verification and validation programs geared to identifying errors earlier in the design and development process will result in more nearly optimum correction of errors. We are also finding that many safety analyses and implementation plans lack the information required for NRC to complete its review. Often omitted are the basis for parameter selection, discussion of data validation, discussion of the human factors design including format examples, 
discussion of the verification and validation program, and discussion of the isolation from electrical or electronic interference with equipment and sensors that are used in safety systems.

\subsection{Summary Observations}

The NRC staff has reviewed the DCRDR Program Plans for a large fraction of the control rooms in nuclear power plants but has reviewed the Summary Reports of completed reviews for only a few control rooms. We have reviewed the SPDS Safety Analyses and Implementation Plans for about one-third of the SPDSs but have conducted no reviews of completed designs. Our observations, therefore, are based more on utility plans and programs that are in progress than on completed programs.

Our observations do not apply to all control rooms or all utility programs but are general impressions based on our review to date. The attitude of a number of utilities is encouraging. They seem more interested in improving their control rooms and providing effective SPDSs than in merely meeting minimum NRC requirements. Operators are deeply involved in many utility DCRDR and SPDS programs. The function and task analyses has probably caused more difficulties than any other DCRDR requirement. We have noted no generic problems in SPDS design. However, we have noted several instances of cluttered displays, labeling, nomenclature, and color conventions at odds with those on the control boards; and verification and validation not included in the early phases of the SPDS development. On the other hand, we have seen some well human factored displays and function-based keyboard designs and some excellent verification and validation programs.

\section{REFERENCES}

1. Kemeny, J. G. (Chairman). Report of the President's Commission on the Accident at Three Mile Island. The President's Commission at 'TMI, Washington, D.C., October 1979.

2. Rogovin, M., Frampton, G. T., Jr., Cornell, E. K., DeYoung, R. C., Budnitz, R., and Norry, P. Three Mile Island: A report to the Commission and to the public. Prepared by Rogovin, Stern, and Huge for the Nuclear Regulatory Commission, January 1980.

3. TMI-2 Lessons Learned Task Force. Final Report (NUREG-0585). Washington, D.C.: Office of Nuclear Reactor Regulation, U. S. Nuclear Regulatory Commission, October 1979.

4. NRC Action Plan Developed as A Result of the TMI-2 Accident (NUREG-0660). U. S. Nuclear Regulatory Commission, May 1980.

5. Guidelines for Control Room Design Reviews (NUREG-0700). U. S. Nuclear Regulatory Commission, September 1981.

6. Mallory, K., Fleger, S., Johnson, J., Avery, L., Walker, R., Baker, D., and Malone, T., Human Engineering Guide to Control Room Evaluation (Draft Report). NUREG/CR-1580. U. S. Nuclear Regulatory Commission.

7. Staff Supplement to the Draft Report on Human Engineering Guide to Control Room Evaluation (NUREG-0659). U. S. Nuclear Regulatory Commission, March 1981.

8. Executive Summary of the Working Conference on Advanced Electrotechnology Applications to
Nuclear Power Plants, Washington, D.C., January 15-17, 1980, Sponsored by IEEE and NRC.

9. Record of the Working Conference on Advanced Electrotechnology Applications to Nuclear Power Plants. Washington, D.C. January 15-17, 1980, sponsored by IEEE and NRC.

10. Conference Record for 1979 IEEE Standards Workshop on Human Factors and Nuclear Safety. Myrtle Beach, South Carolina, December 2-7, 1979, Institute of Electrical and Electronic ngineers.

11. Conference Record for 1981 IEEE Standards Workshop on Human Factors and Nuclear Safety. Myrtle Beach, South Carolina, August 30-September 4, 1981, Institute of Electrical and Electronics Engineers.

12. Clarification of TMI Action Plan Requirements Requirements for Emergency Response Capability (NUREG-0737, Supplement 1). U. S. Nuclear Regulatory Commission, December 1982.

13. Meeting Summary - Task Analysis Requirements of Supplement I to NUREG-0737, March 29, 1984, Meeting with Westinghouse Owners' Group (WOG) Procedures Subcommittee and Other Interested Parties. Memorandum from H. Brent Clayton to Dennis L. Ziemann, U. S. Nuclear Regulatory Commission, April 5, 1984.

14. Meeting Sumary - Task Analysis Requirements of Supplement 1 to NUREG-0737, May 4, 1984, Meeting with BWR Owners' Group Emergency Procedure Guidelines and Control Room Design Review Committees. Memorandum from S. H. Weiss to Voss A. Moore, U. S. Nuclear Regulatory Commission, May 14, 1984.

15. Meeting Summary - Task Analysis Requirements of Supplement I to NUREG-0737, August 29, 1984, Meeting with Combustion Engineering Owners' Group (CEOP) Operations Subcommittee. Memorandum from H. Brent Clayton to Dennis L. Ziemann, U. S. Nuclear Regulatory Commission, September 7, 1984.

16. Verification and Validation for Safety Parameter Display System, Prepared by Science Applications, Inc. for Nuclear Safety Analysis Center, NSAC-39, December 1981. 